Article

\title{
Implementation of Safety Management System for Improving Construction Safety Performance: A Structural Equation Modelling Approach
}

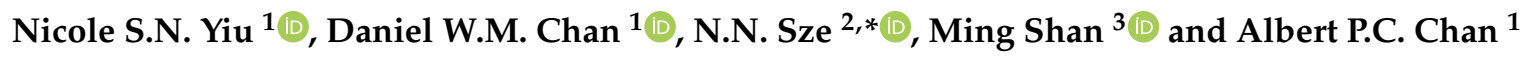 \\ 1 Department of Building and Real Estate, The Hong Kong Polytechnic University, Hung Hom, Hong Kong, \\ China; nico.yiu@polyu.edu.hk (N.S.N.Y.); daniel.w.m.chan@polyu.edu.hk (D.W.M.C.); \\ albert.chan@polyu.edu.hk (A.P.C.C.) \\ 2 Department of Civil and Environmental Engineering, The Hong Kong Polytechnic University, Hung Hom, \\ Hong Kong, China \\ 3 School of Civil Engineering, Central South University, 68 South Shaoshan Road, Changsha 410075, China; \\ ming.shan@csu.edu.cn \\ * Correspondence: tony.nn.sze@polyu.edu.hk; Tel.: +852-2766-6062
}

Received: 25 March 2019; Accepted: 17 April 2019; Published: 18 April 2019

check for updates

\begin{abstract}
The construction industry contributes to a large proportion of industrial injury and mortality. It is of high importance to evaluate the effectiveness of the Safety Management System (SMS). In particular, it is necessary to compare the quality and level of achievement of SMS and safety performance of a construction project. However, a sizeable sample of construction accidents is often not available. Therefore, possible proxies to indicate the safety performance were established. Moreover, the motivation factors which characterize the quality and level of achievement should be identified. In this study, a structural model has been established to examine the relationship between the SMS implementation and operational \& safety performance of the construction projects. Results of the structural model illustrated the relationship between (i) SMS implementation and project safety outcome, (ii) SMS implementation and five motivation factors, and (iii) project safety outcome and six proxies. Results of this study have unfolded the motivation factors in SMS implementation and their subsequent effects on project performance, throwing light on the need to enhance the safety management practice in order to reduce accidents and injuries in the construction industry in the long run.
\end{abstract}

Keywords: construction safety; safety management system; Structural Equation Model; project management

\section{Introduction}

Safety management system (SMS) was introduced in the European Union to promote safety and health improvements in the workplace in the 1980s [1-3]. In accordance with the Framework Directive on Risk Assessment and Risk Management implemented in 1989, Health and Safety Executives of United Kingdom and a number of European Union member states empowered the development and implementation of SMS through legislation during the period from 1989 to 1992 [3,4]. In general, accidents on construction sites contribute to a large proportion of industrial accidents around the world. In Japan, South Korea, Singapore and Hong Kong, accidents on construction sites constituted about $20 \%$ of industrial accidents during the period between 1995 and 2005 [5,6]. To tackle the problem of high accident and mortality risks on construction sites, SMS (mandatory or voluntary) for building and construction has been introduced in many countries since the 1990s [6]. 
SMS has been introduced worldwide, targeted at accident and injury reduction on construction sites. It is of essence to evaluate the safety effectiveness of SMS, given the possible constraints including financial budget, legislation and contractual and operational obligation. Indeed, accidents and mortality are rare and of a random nature. It is not common that a sizeable sample is available for efficient safety analysis. Evidence could hardly be established for the association between SMS and safety effectiveness (in terms of accident and mortality reduction) [3,5,7]. Some proxies and surrogate measures (other than accident and injury incidence) can indicate the safety effectiveness.

Additionally, it is necessary to understand the effects of underlying factors that affect the SMS implementation and therefore the anticipated safety improvement. In particular, the possible factors contributing to the quality and level of achievement of SMS should be identified. For the quality, SMS depends on the organizational characteristics of the company, project and personnel; and for the achievement level, SMS depends on the extent of completion of possible safety initiatives. To proxy the safety outcome, a number of indicators for the environmental, operational and personal characteristics of an organization and project could be set out [8]. There were a number of motivation factors identified through qualitative approaches, e.g., literature review and structural interview with the professionals [9]. These factors characterize the quality and level of achievement of SMS and the proxies (or outcomes) which reflect the operational and safety performances. Therefore, the purpose of this study is to evaluate the effectiveness of SMS implementation in improving the safety of construction projects. Additionally, the motivation factors and project indicators that can proxy the SMS implementation and safety performance should be identified.

In Hong Kong, the legal requirement of SMS was imposed in 1999. As a rapidly growing global city in Asia, the volume of construction (in the terms of project sum and workers engaged) had been high in Hong Kong over the past two decades. On average, the annual infrastructure spending (around US $\$ 10$ billion) constituted over 18\% of the total government expenditure in Hong Kong. Over 120,000 manual workers ( $3 \%$ of total labour force) engaged in the construction sector [10]. In 2017, the death toll related to construction reached 22 in the Hong Kong construction industry. The data about disaggregated fatality and accident numbers by project or site are not sufficient for sensible analysis (there were 108 road fatalities in the same period) [11]. In this study, we applied the empricial data about the construction industry in Hong Kong to evaluate the safety effectiveness of SMS implementation. Since the total contract sum of construction projects and density of infastructure development are high in Hong Kong, results of this study should be impactful in the area, given the constraints of financial budget, legal requirements (both mandatory and voluntary) and contractual obligation [9].

The remainder of the paper is structured as follows. Section 2 describes the findings of literature review. The formulation and results of proposed Structural Equation Model for the association between implementation (quality and level of achievement) and safety effectiveness are given in Sections 3 and 4 respectively. Eventually, Section 5 provide recommendations and concluding remarks respectively.

\section{Literature Review}

\subsection{Construction Safety and SMS}

Building and construction has long been considered as a risky industry. It involves numerous dangerous and difficult work tasks, e.g., lifting operation and working at height, etc. The accident rate is considered to be a common metric for benchmarking the construction safety performance. Contractors were always required to record the incidents and injuries that happened on the construction sites, and report to the client and public authority [9,12]. Globally, more than 2.78 million people die in occupational accidents and work-related diseases every year [13]. In Hong Kong, all workplace injuries have to be reported to the Labour Department within the designed timeline [11]. Figure 1 illustrates the occupational accident rates in three major industries in Hong Kong during the period from 1996 to 2016. As shown in Figure 1, accident rates in building and construction were always higher than that in the catering and manufacturing sectors. Despite that, sustainable reduction in accident rates could 
be revealed. For instance, of the 3902 construction accidents in 2017, over three-quarters were related to circumstances including slip and fall on the same level, lifting or carrying, fall from height, and striking against moving or stationary objects. Besides, of the construction-related fatalities, the majority was attributed to falling from height and being stricken by a moving vehicle [11,14].

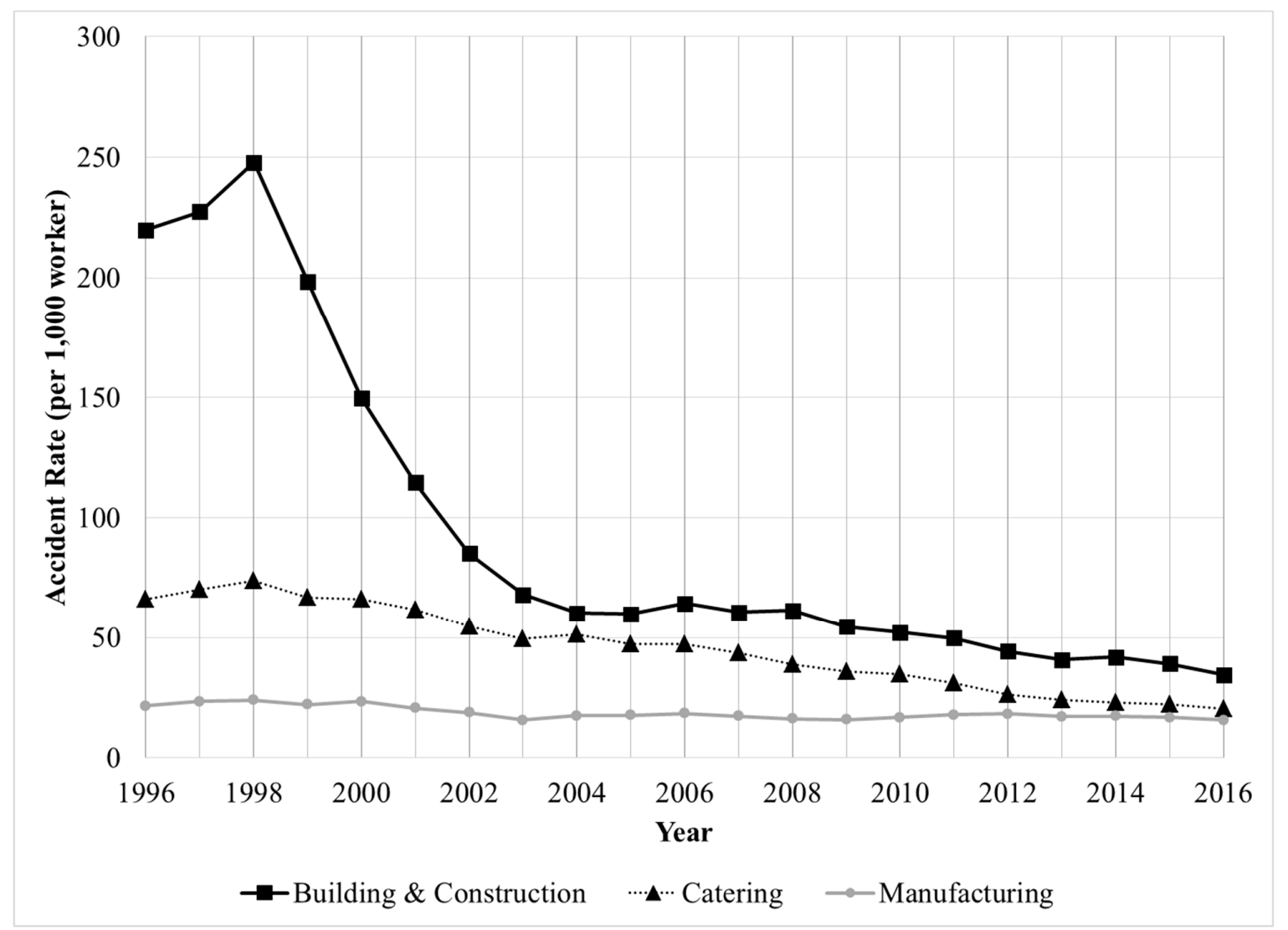

Figure 1. Accident Rates of Three Major Industries in Hong Kong (1996-2016).

Safety Management System (SMS) refers to a systematic framework to facilitate the health and safety management at the workplace [4]. SMS has been introduced in more than 20 countries. A number of studies have attempted the safety effectiveness of SMS for a single company and/or project, identifying the elements contributing to the deficiency of existing hazard management systems. For instance, it was suggested that integrating the SMS and existing quality assurance system would be essential to enhance the project performance. Furthermore, a robust conceptual framework for the integration was proposed $[15,16]$. However, the framework established without strong linkage of the current practices of SMS in construction projects. It is rare that a comprehensive framework for SMS implementation in the construction industry, with which a number of personnel are involved, and project sum are much higher, has been attempted. Yet, a qualitative study on the motivation factors for SMS implementation in the construction sector has been conducted by the same research team [6]. However, a quantitative analysis on the association between implementation and safety performance based on empirical data would be desirable. Also, we attempt to verify that the factors revealed in preceding qualitative study are efficient and effective indicators to SMS implementation and safety performance of construction project respectively, using a structural model.

For the application of SMS in the construction industry, studies have attempted the difficulties and challenges for the implementation. It was suggested that a robust safety management system had potential in eliminating the hazards on construction sites, especially enhancing the risk perception and awareness of construction workers [17]. The Labour Department of the Hong Kong Government has developed a systematic SMS framework, by incorporating the standards specified in 
a number of international standards, including BS8800:1996 Guide to occupational health and safety management systems, AS/NZS4360:1995 Australian/New Zealand Standard on Risk Management, OHSAS 18001:1999 Occupational health and safety management systems Specification, and OHSAS 18002:1999 Occupational health and safety management systems Guidelines for the implementation of OHSAS 18001 [11]. In particular, the framework provides the details on the principles and road maps for the development and practical application on construction sites [18]. In Hong Kong, the SMS framework consists of 14 functional elements, plus one audit and review protocol. The 15 elements are (1) safety policy, (2) safety organization, (3) safety and health training programme, (4) in-house safety and health rules, (5) safety inspection programme, (6) hazard control by the use of personal protective equipment (PPE), (7) incident investigation programme, (8) emergency preparedness programme, (9) control of sub-contractors, (10) safety committees, (11) job hazard analysis, (12) safety promotion programme, (13) process control programme, (14) occupational health assurance programme, (15) safety audit and review. The above are consistent with the international standards established in other jurisdictions and are transferable to construction projects outside Hong Kong [12,19].

For the practical implementation, the SMS compliance is usually assessed by the independent qualified auditors. Reliability and robustness of the safety audit depends on the framework of implementation [19]. 'Safety audit' is considered a positive feedback loop and helps to reinforce the SMS implementation. The capacity of SMS can be maximized for risk reduction in the construction sector [12]. Yet, the safety audit alone in fact indicated the level of conformity only. It is necessary to measure the relationship between safety compliance and safety performance $[9,19]$. Another possible safety performance indicator is accident rate. Accident rate is usually recorded by main contractors and reported to the client and government. It is usually referred as per thousand worker accident number or per million man-hour accident number $[9,12,13]$. However, to shift the focus from response-based to prevention-based risk reduction, project performance indicators other than accident rate should be developed [8].

\subsection{Motivation Factors to Enhance the Quality and Level of Achievement of SMS Implementation}

SMS for construction sector covers a wide spectrum of safety measures for the project cycle from the planning, development, institutional organization and execution. It also covers different scopes of work including safety and health training, in-house safety rules, safety inspection programmes, job hazard control and analysis, incident investigation programme, emergency preparedness programme, occupational safety promotion, and health assurance programme, etc. They are to eliminate the possible workplace safety hazards and reduce the accident risk on construction site. A number of motivation factors were revealed to be contributing to the quality and level of achievement of SMS implementation. These motivation factors for SMS implementation could be categorized into five different classes (refer to Table 1), i.e., safety management commitment, competency profiles of project personnel, safety climate, project management, and safety requirements and incentives [9]. For instances, management's commitment could enhance the awareness of workers and safety supervisors, while the competence of project personnel could facilitate the assurance and execution $[8,9,14]$. In addition, safety climate was found correlated to the safety outcome of construction project, in the terms of construction incident and injury [20-22]. Moreover, communication between management, safety supervisors and workers could be improved with the good project management [8,20,23-25]. Last but not the least, clear guidelines for safety implementation could increase the level of transparency between the expectation of management and concerns of workers and supervisors $[8,14,21,22,26]$. The above all motivation factors were identified to be important for the SMS implementation as well as potentially influencing the construction safety. Yet, quantitative analysis for the association between actual project outcomes and possible factors would be essential. 
Table 1. Constructs and Initial Measurement Attributes for Motivation Factors of SMS.

\begin{tabular}{|c|c|c|}
\hline Factors & Attributes & References \\
\hline $\begin{array}{l}\text { Safety Commitment by Senior } \\
\text { Management (MF1) }\end{array}$ & $\begin{array}{l}\text { MF1.1 Joined the regular safety inspections and safety } \\
\text { committee meetings by the senior management } \\
\text { MF1.2 Allocated adequate and competent manpower to } \\
\text { complete the job tasks safely } \\
\text { MF1.3 Spent sufficient cost on purchasing appropriate plant } \\
\text { and equipment for carrying the work safely } \\
\text { MF1.4 Provided with adequate time to complete the assigned } \\
\text { job tasks safely }\end{array}$ & {$[8,14,21,23,26-35]$} \\
\hline Competency Profiles (MF2) & $\begin{array}{l}\text { MF2.1 Demonstrated safety leadership by the senior } \\
\text { management } \\
\text { MF2.2 Appointed qualified and competent safety manager } \\
\text { (or safety-in-charge of the project) } \\
\text { MF2.3 Appointed qualified project manager with good } \\
\text { safety behaviors } \\
\text { MF2.4 Appointed subcontractors who are competent in OSH } \\
\text { MF2.5 Demonstrated correct concepts and understanding of } \\
\text { accident prevention by the society, public media, } \\
\text { governmental officers, workers' unions and politicians, etc. }\end{array}$ & {$[8,14,20,33,36,37]$} \\
\hline Safety Climate (MF3) & $\begin{array}{l}\text { MF3.1 Participated in safety issues actively by employees, } \\
\text { including workers } \\
\text { MF3.2 Demonstrated strong safety culture of the } \\
\text { construction project } \\
\text { MF3.3 Appointed key project management personnel, such as } \\
\text { project manager, site agent, safety manager, with higher } \\
\text { safety awareness } \\
\text { MF3.4 Recruited workers with higher safety awareness } \\
\text { MF3.5 Demonstrated correct safety values of the society, } \\
\text { public media, governmental officers, workers' unions and } \\
\text { politicians, etc. }\end{array}$ & {$[8,20-22,27]$} \\
\hline $\begin{array}{l}\text { Project Management } \\
\text { (MP4) }\end{array}$ & $\begin{array}{l}\text { MCF4.1 Well-scheduled and communicated project meetings } \\
\text { which included intensive involvement of engineers in } \\
\text { safety issues } \\
\text { MF4.2 Well-coordinated teamwork } \\
\text { MF4.3 Well-functioned communication system, starting from } \\
\text { design stage to completion stage } \\
\text { MF4.4 Well-planned construction works, such as } \\
\text { well-designed construction methods, with the consideration of } \\
\text { site constraints } \\
\text { MF4.5 Adopted safety organization showing the } \\
\text { responsibilities and accountabilities of key personnel } \\
\text { MF4.6 Selected and monitored the subcontractors strategically } \\
\text { MF4.7 Consultation of the ideas and suggestions of the } \\
\text { risk stakeholders. } \\
\text { MF4.8 Adopted mechanism to carry out serious accident } \\
\text { investigation by a competent team of experts }\end{array}$ & {$[8,20,23-25]$} \\
\hline $\begin{array}{l}\text { Safety Requirements and } \\
\text { Incentives (MF5) }\end{array}$ & $\begin{array}{l}\text { MF5.1 Fulfilled safety related legislations } \\
\text { MF5.2 Fulfillled the contractual and client requirements } \\
\text { MF5.3 Received incentives internally or from client for the } \\
\text { purpose of site safety promotion }\end{array}$ & {$[8,14,21,22,26]$} \\
\hline
\end{tabular}

\subsection{Proxies Indicating Safety Performance}

Prevalence and severity of construction incidents are the most relevant and direct construction safety indicators. However, construction accidents are rare and randomly distributed. Aggregation of accident cases across considerable time period and numerous projects would be required to generate a sizeable sample for efficient analysis. To tackle this problem, a number of surrogate measures and safety performance metrics have been developed [9]. For instance, project outcomes in terms of six types of project characteristics and 25 factor attributes (as shown in Table 2) were established. They are safe working environment (PC1) [38,39], well operated construction activities (PC2) [20,38,39], positive indications from key performance indicators (PC3) [20,23], desirable qualities of individuals 
(PC4) $[23,39]$, well-fitted procedures and manuals (PC5) [20,36,38,39], and supportive safety compliance and incentive schemes (PC6) $[20,23,36,39]$. Safe working environment and construction operation could eliminate the hazards associated with the working conditions, construction methods and work procedures $[20,38,39]$. Positive key performance indicators implied the safety commitment of the project teams [20,23]. Qualification of project manager and safety supervisor could assure the compliance of safety requirements, and thus the implementation of appropriate hazard control and elimination measures on the construction site [9,23,39]. Appropriate operation procedures and clear instructions could facilitate the communication between project manager, safety supervisor and labour, and thus avoid the non-compliance of safety requirements $[9,20,36,38,39]$. Last but not least, effective incentive schemes could stimulate the compliance of project team, and achieve sustainable safety improvement $[20,23,36,39]$.

Table 2. Constructs and Initial Measurement Attributes for Project Outcomes.

\begin{tabular}{|c|c|c|}
\hline Factors & Attributes & References \\
\hline $\begin{array}{l}\text { Safe Working Environment/ } \\
\text { Conditions (PC1) }\end{array}$ & $\begin{array}{l}\text { PC1.1 Provided and maintained good housekeeping } \\
\text { PC1.2 Implemented and maintained good site physical } \\
\text { conditions to ensure safe working environment } \\
\text { PC1.3 Provided adequate protection to site materials during } \\
\text { transportation and storage } \\
\text { PC1.4 Showed care to people by the project management, such } \\
\text { as provision of sufficient rest time }\end{array}$ & {$[38,39]$} \\
\hline $\begin{array}{l}\text { Well-Operated Construction } \\
\text { Activities (PC2) }\end{array}$ & $\begin{array}{l}\text { PC2.1 Well-planned construction methods and use of plant } \\
\text { and equipment. } \\
\text { PC2.2 Arranged the delivery and storage of site materials to } \\
\text { facilitate the project execution } \\
\text { PC2.3 Well-understood sequences of construction work } \\
\text { activities by all concerned project staff and workers } \\
\text { PC2.4 Instructed, controlled and reviewed construction site } \\
\text { activities effectively } \\
\text { PC2.5 Well-functioned communication system } \\
\text { PC2.6 Demonstrated higher teamwork spirit }\end{array}$ & {$[20,38,39]$} \\
\hline $\begin{array}{l}\text { Positive Indications from Key } \\
\text { Performance Indicators (PC3) }\end{array}$ & $\begin{array}{l}\text { PC3.1 Showed a decreasing trend of accident rates or } \\
\text { maintained low accident rates } \\
\text { PC3.2 Showed strong financial performance } \\
\text { PC3.3 Maintained high participation rates in safety and health } \\
\text { activities by employees } \\
\text { PC3.4 Maintained strong safety culture }\end{array}$ & {$[20,23]$} \\
\hline $\begin{array}{l}\text { Desirable Qualities of } \\
\text { Individuals (PC4) }\end{array}$ & $\begin{array}{l}\text { PC4.1 Received high education level by workers } \\
\text { PC4.2 Demonstrated high safety awareness by project manager } \\
\text { PC4.3 Demonstrated high safety awareness by top } \\
\text { management of the firm } \\
\text { PC4.4 Demonstrated good sense of belonging by employees } \\
\text { PC4.5 Recruited competent workers to work safely }\end{array}$ & {$[23,39]$} \\
\hline $\begin{array}{l}\text { Well-fitted Procedures and } \\
\text { Manuals (PC5) }\end{array}$ & $\begin{array}{l}\text { PC5.1 Clearly-defined responsibilities and accountabilities in } \\
\text { the safety organization } \\
\text { PC5.2 Provided and enforced strict operating procedures } \\
\text { PC5.3 Provided and make assessable of site safety manual } \\
\text { to employees }\end{array}$ & {$[20,36,38,39]$} \\
\hline $\begin{array}{l}\text { Supportive Safety Compliance } \\
\text { and Incentive Schemes (PC6) }\end{array}$ & $\begin{array}{l}\text { PC6.1 Offered incentives for employees' participation in safety } \\
\text { and health activities } \\
\text { PC6.2 Enforced safety regulations strictly } \\
\text { PC6.3 Demonstrated support and commitment by senior } \\
\text { management such as joining inspection meeting and } \\
\text { inspection; allowing budgets to carry out the works safely }\end{array}$ & {$[20,23,36,39]$} \\
\hline
\end{tabular}

\subsection{Remarks}

The identified perceived benefits and potential difficulties of SMS implementation were based on the state-of-the-practice review and structured interviews of practitioners [9]. The perceived benefits were accident reduction, improvement in safety audit compliance, and better cost allocation and 
project management. In contrast, the potential difficulties and challenges were high stress for project completion and high turnover rates of labor. Yet, the challenges were suspected for being closely related to the SMS implementation. It is controversial for the remarkable positive effects of SMS implementation, without the support by empirical evidence on the association between motivation factors of SMS implementation, and possible operational and safety performance attributes. In this study, a structural model will be established to measure the association between motivation factors, quality and level of achievement of SMS implementation, and proxies for better operational and safety performances. Therefore, the safety effectiveness of SMS implementation can be evaluated.

\section{Structural Equation Model}

\subsection{Data}

The data was collected using questionnaire surveys to practitioners. The attributes considered were set out based on the findings of previous study by the same research team [9]. The questionnaire consists of three sections: (i) Background information including year of working experience, project particulars, and SMS implementation attributes; (ii) SMS compliance and motivation factors including safety climate, commitment, management strategies and project incentives; and (iii) Project performance outcomes. For the sections on motivation factors and project outcomes, a five-point Likert rating scale was used. To ensure the robustness of the questionnaire, a preliminary questionnaire was assessed by six experienced practitioners in the field.

The questionnaire survey was conducted during the period between August 2016 and February 2017. Safety practitioners were invited to participate in the questionnaire survey. Participants included representatives from client firms, contractors, and consultants in Hong Kong. To push up the response rate and avoid the bias of non-response, four local construction and safety authorities and associations were approached and assisted the questionnaire survey, namely the Hong Kong Construction Association, Construction Industry Council, Society of Registered Officers, Hong Kong Occupational Safety and Health Association. The respondents consisted of client and developer, main contractor, sub-contractor, safety consultant, and supplier. The inclusion criterion was having experience of SMS implementation. A total of 334 completed and valid questionnaires were received. Table 3 shows descriptive statistics of participated respondents. Of the 334 respondents, $64.4 \%$ were main contractors, $29.6 \%$ were clients, developers, governmental agencies and safety consultants, and $6 \%$ were subcontractor and suppliers respectively. With respect to years of experience of SMS implementation, of the 334 respondents, $70.1 \%$ had 10 years or more experience. Regarding the project particular, of the 334 observations, $37.4 \%$ had less than 100 workers on site, while $62.6 \%$ had more than 100 workers respectively. This also indicated that despite the project size, an SMS was implemented to monitor workplace hazards in most of the respondents' construction projects.

Table 3. Descriptive Statistics of the Participated Respondents.

\begin{tabular}{lcccc}
\hline & Minimum & Maximum & Mean/ Count (\%) & Standard Deviation \\
\hline Main contractor & N/A & N/A & $215(64.4 \%)$ & N/A \\
\hline Client & N/A & N/A & $99(29.6 \%)$ & N/A \\
\hline Sub-contractor & N/A & N/A & $20(6.0 \%)$ & N/A \\
\hline Number of workers & 0 & 300 & 152.56 & 125.89 \\
\hline Number of external safety audit & 0 & 5 & 2.11 & 1.4 \\
\hline Number of internal safety audit & 0 & 5 & 2.25 & 1.53 \\
\hline Number of accidents & 0 & 5 & 0.90 & 1.24 \\
\hline Safety Practitioners & N/A & N/A & $127(38.0 \%)$ & N/A \\
\hline Project staff & N/A & N/A & $207(62.0 \%)$ & N/A \\
\hline Working experience & 0 & 15 years & 13.23 & 5.23 \\
\hline Working experience in SMS & 0 & 15 years & 10.91 & 5.91 \\
\hline
\end{tabular}




\subsection{Model Formulation}

In this study, a Structural Equation model will be established to measure the association between quality and level of achievement of SMS implementation, project operational and safety performance, and the associated attributes. The factor attributes were set out based on the literature review and structured interview in the preceding study by the same research team [9]. As shown in Table 2, 25 motivation factors to better SMS implementation were identified and were grouped into five categories, namely safety commitment, competency profile, safety climate, project management, and safety requirement. For instance, Safety commitment by senior management (Category 1) was characterized by factor attributes like "visible senior management commitment" and "cost spent on safety issues" [8,14,21,23,26-29,31-35]. Competency profiles (Category 2) referred to factor attributes like personal quality and competency of safety manager and safety leadership of senior management $[8,14,20,33,36,37]$. Safety climate (Category 3 ) referred to factor attributes including safety awareness of employees and key personnel [8,20-22,27]. Project management (Category 4) could be constituted by effective communication system and strategic monitoring of site operation [8,20,23-25]. Safety requirements and incentives (Category 5) referred to the external factors such as financial incentives, legal requirements, contractual requirements and accreditation requirements of construction projects $[8,14,21,22,26]$.

It is expected that the implementation quality and level as characterized by the aforementioned factors would correlate with the project operational and safety performance. As shown in Table 3, 25 project operational and safety performance proxies were identified by literature reviews and structured interviews in the preceding study. These attributes can be grouped into six categories, namely safe working environment, well-operated construction activities, positive key performance indicators, desirable quality of key individuals, well-fitted procedures and manuals and supportive safety compliance and incentive schemes. In particular, safe working environment/conditions (Category 1) can be characterized by good housekeeping and physical conditions [38,39], positive indications from key performance indicators (Category 2) can be reflected by low accident rates, strong financial performance, high employees participation rates in safety and health activities, and strong safety culture [20,23], well-operated construction activities (Category 3) referred to well-planned construction methods, proper arrangement logistic arrangement of site material delivery and effective communication system [20,38,39], desirable qualities of individuals (Category 4) were indicated by awareness of senior management, competent workmanship and good sense of belongings for individuals [23,39], well-fitted procedures and manuals (Category 5) included clearly defined responsibilities and accountabilities, availability of operating procedures and safety manual [20,36,38,39], and supportive safety compliance and incentive schemes (Category 6) included the compliance of safety regulations, incentives offered in safety promotion activities and support by senior management $[20,23,36,39]$ respectively.

In the proposed study, all the aforementioned factor attributes will be incorporated. It is to evaluate the relative significance of individual attributes contributing to the SMS implementation and promising operational and safety performance. The strength of the links between (i) individual motivation factors and SMS implementation; (ii) individual project outcome and attributes; and (iii) SMS implementation and safety outcome, as illustrated in Figure 2, would be assessed using a Structural Equation model. In particular, SMS implementation (quality and achievement) and safety effectiveness (operational and safety performances) are latent constructs. 


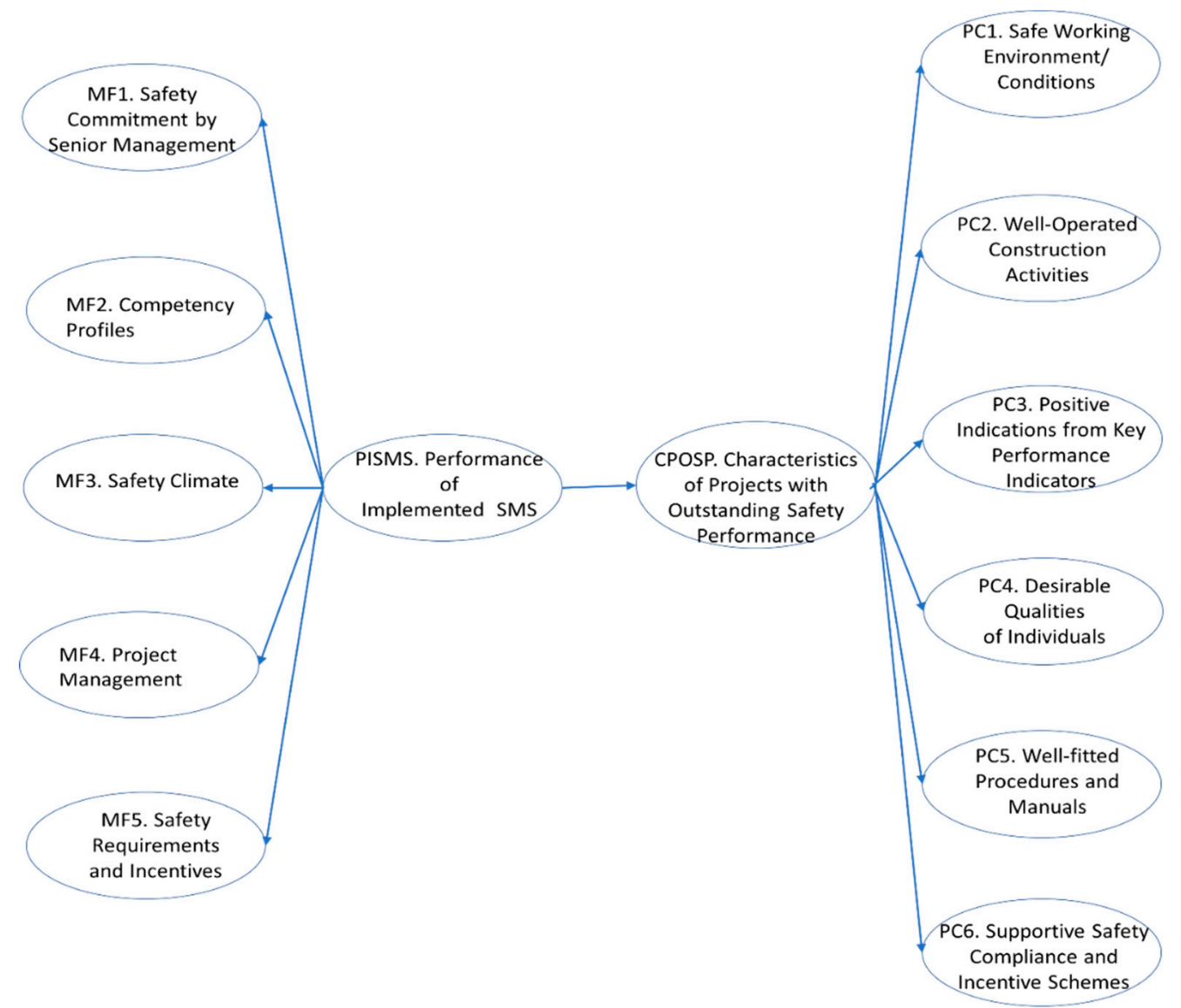

Figure 2. Proposed Structural Model for the Association between Motivation Factor and Project Outcomes.

The purpose of current study is to identify the key 'driver' constructs, i.e., SMS implementation and safety proxies of construction project. The Partial Least Square Structural Equation model (PLS-SEM) will be applied to evaluate the relationship between key constructs [40]. It is required that the minimum sample size for PLS-SEM is 10 times of the number of structural paths directed to the latent construct having the highest number of structural paths in the model [40]. In the current study, the latent construct with the highest number of structural paths is project safety outcome. The minimum required sample size is 60 . As the sample size is 334 , the minimum sample size requirement of PLS-SEM is satisfied. More importantly, PLS-SEM has the flexibility for not requiring any prevailing correlation between latent construct and the relevant factor attributes, and assumptions of statistical distributions of factor attributes [40]. Referring to the model formulation and modelling mechanism, partial least squares (PLS) approach is superior to ordinary least squares, canonical correlation, and covariance-based approaches. PLS allows models with multiple dependent and independent variables, is capable to handle multi-collinearity problem; and creates independent latent variables directly based on cross-products involving the response variable(s). PLS-SEM model is generally considered as a viable alternative to traditional covariance-based Structural Equation model (CB-SEM). In this study, the modelling package SmartPLS 3.0 was used to establish the proposed PLS-SEM path model. The analytic framework of SmartPLS 3.0 can be stratified into two stages: (1) score estimation of latent constructs of initial model; and (2) path coefficient estimation of final model. To evaluate the goodness-of-fit (GoF) of proposed PLS-SEM, indicators including Composite Reliability (CR) for internal consistency reliability, indicator loading for indicator reliability, and Average Variance Extracted (AVE) for convergent validity will be estimated [40,41]. In particular, as shown in Table 4, the thresholds for good fit are: (Rule 1) CR greater than 0.7; (Rule 2) indicator loading greater than 0.7; (Rule 3) AVE greater than 0.5; and (Rule 4) indicator loading greater than cross loading [40]. 
Table 4. Rules of Goodness-of-fit Assessment and Model Estimates.

\begin{tabular}{llll}
\hline Rule & Aspects & Indicators & Threshold \\
\hline \multicolumn{2}{l}{ Reflective Measurement Model } & & \\
\hline R1 & Internal consistency reliability & Composite reliability (CR) & $>0.70$ \\
\hline R2 & Indicator reliability & Indicator loadings & $>0.70$ \\
\hline R3 & Convergent validity & $\begin{array}{l}\text { Average variance extracted } \\
\text { (AVE) }\end{array}$ & $>0.50$ \\
\hline R4 & Discriminant validity & Indicator loadings & $>$ Cross loadings \\
\hline Formative Measurement Model & & \\
\hline R5 & Significance of individual indicator & t-values for a two-tailed test & 1.96 (5\% level of significance) \\
\hline
\end{tabular}

\section{Results and Discussions}

\subsection{Analysis Results}

PLS-SEM approach was used to evaluate the relationship between the safety surrogate measures and motivation factor of SMS implementation, and the associated attributes. The number of observation of the model was 334. The proposed PLS-SEM generally fit well. As shown in Table 5, values of CR and AVE were all greater than 0.7 (Rule 1) and 0.5 (Rule 3) for all factor attributes respectively. This implied the high internal reliability and convergent validity.

Table 5. Composite Reliability (CR) and Average Variance Extracted (AVE) of the Structural Model.

\begin{tabular}{lll}
\hline & CR & AVE \\
\hline Motivation Factor & 0.969 & 0.558 \\
\hline MF1. Safety Commitment by Senior Management & 0.888 & 0.666 \\
\hline MF2. Competency Profiles & 0.902 & 0.648 \\
\hline MF3. Safety Climate & 0.946 & 0.778 \\
\hline MF4. Project Management & 0.951 & 0.706 \\
\hline MF5. Safety Requirements and Incentives & 0.906 & 0.763 \\
\hline Project Outcome & 0.972 & 0.579 \\
\hline PC1. Safe Working Environment/ Conditions & 0.905 & 0.705 \\
\hline PC2. Well-Operated Construction Activities & 0.946 & 0.744 \\
\hline PC3. Positive Indications from Key Performance Indicators & 0.896 & 0.683 \\
\hline PC4. Desirable Qualities of Individuals & 0.916 & 0.686 \\
\hline PC5. Well-fitted Procedures and Manuals & 0.921 & 0.796 \\
\hline PC6. Supportive Safety Compliance and Incentive Schemes & 0.916 & 0.783 \\
\hline
\end{tabular}

For the path coefficient, as shown in Table 6 and Figure 3, all path links were found significant at the $1 \%$ level (Rule 5, with t-statistic all greater than 2.58 for two-tailed test). This implied that all the paths between the latent constructs and concerned factor attributes of the proposed Structural model were valid. 
Table 6. Results of path coefficient estimates of the Structural Model.

\begin{tabular}{ccc}
\hline Paths & Path Coefficient & t-Statistic \\
\hline $\mathrm{MF} \rightarrow$ PC & 0.915 & $19.449^{*}$ \\
\hline $\mathrm{MF} \rightarrow$ MF1 & 0.848 & $33.886^{*}$ \\
\hline $\mathrm{MF} \rightarrow$ MF2 & 0.895 & $58.518^{*}$ \\
\hline $\mathrm{MF} \rightarrow$ MF3 & 0.895 & $63.448^{*}$ \\
\hline $\mathrm{MF} \rightarrow$ MF4 & 0.938 & $97.236^{*}$ \\
\hline $\mathrm{MF} \rightarrow$ MF5 & 0.774 & $22.026^{*}$ \\
\hline $\mathrm{PC} \rightarrow$ PC1 & 0.861 & $36.183^{*}$ \\
\hline $\mathrm{PC} \rightarrow$ PC2 & 0.914 & $55.869^{*}$ \\
\hline $\mathrm{PC} \rightarrow$ PC3 & 0.899 & $73.911^{*}$ \\
\hline $\mathrm{PC} \rightarrow$ PC4 & 0.916 & $88.648^{*}$ \\
\hline $\mathrm{PC} \rightarrow$ PC5 & 0.897 & $80.501^{*}$ \\
\hline $\mathrm{PC} \rightarrow$ PC6 & 0.842 & $39.651^{*}$ \\
\hline
\end{tabular}

* Significance at the $1 \%$ level.

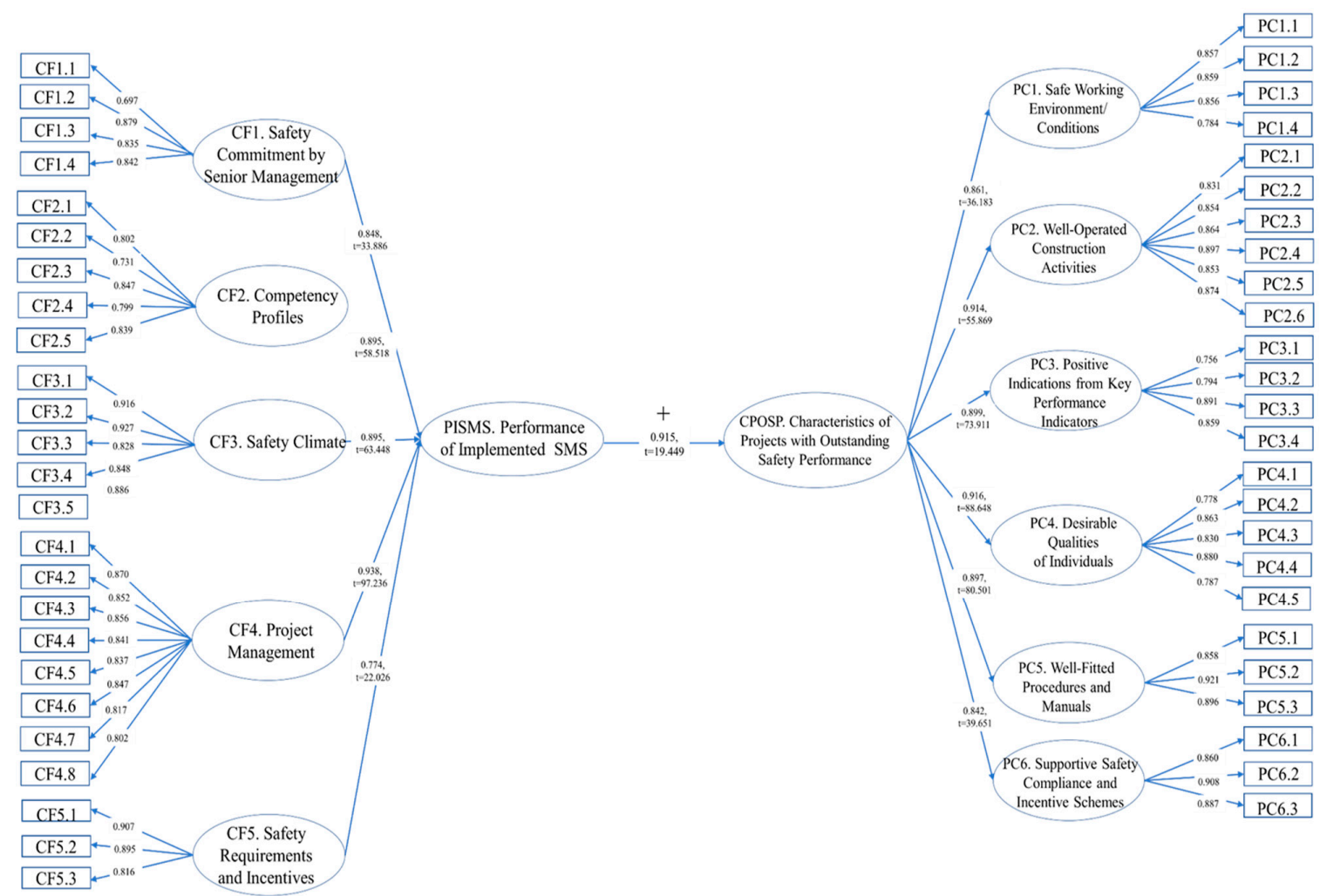

Figure 3. Path Estimates of the Structural Model.

\subsection{Motivation Factors to Quality and Level of Achievement of SMS Implementation}

As shown in Table 7, values of indicator loading were greater than 0.7 (Rule 2) for all factor attributes (except MF 1.1 with indicator loading of 0.697). Also, the values of indicator loading were greater than that of cross loading for all factor attributes (Rule 4). This implied the high indicator reliability and discriminant validity. 
Table 7. Indicator loading and cross loading of motivation factor attributes.

\begin{tabular}{llllll}
\hline & MF1 & MF2 & MF3 & MF4 & MF5 \\
\hline MF1.1 & $\mathbf{0 . 6 9 7}$ & 0.584 & 0.484 & 0.436 & 0.548 \\
\hline MF1.2 & $\mathbf{0 . 8 7 9}$ & 0.680 & 0.580 & 0.641 & 0.572 \\
\hline MF1.3 & $\mathbf{0 . 8 3 5}$ & 0.624 & 0.574 & 0.610 & 0.473 \\
\hline MF1.4 & $\mathbf{0 . 8 4 2}$ & 0.648 & 0.593 & 0.630 & 0.510 \\
\hline MF2.1 & 0.676 & $\mathbf{0 . 8 0 2}$ & 0.637 & 0.594 & 0.527 \\
\hline MF2.2 & 0.481 & $\mathbf{0 . 7 3 1}$ & 0.442 & 0.443 & 0.369 \\
\hline MF2.3 & 0.606 & $\mathbf{0 . 8 4 7}$ & 0.579 & 0.601 & 0.474 \\
\hline MF2.4 & 0.636 & $\mathbf{0 . 7 9 9}$ & 0.677 & 0.693 & 0.491 \\
\hline MF2.5 & 0.698 & $\mathbf{0 . 8 3 9}$ & 0.718 & 0.735 & 0.530 \\
\hline MF3.1 & 0.644 & 0.695 & $\mathbf{0 . 9 1 6}$ & 0.719 & 0.591 \\
\hline MF3.2 & 0.646 & 0.692 & $\mathbf{0 . 9 2 7}$ & 0.736 & 0.605 \\
\hline MF3.3 & 0.540 & 0.680 & $\mathbf{0 . 8 2 8}$ & 0.632 & 0.540 \\
\hline MF3.4 & 0.565 & 0.668 & $\mathbf{0 . 8 4 8}$ & 0.640 & 0.432 \\
\hline MF3.5 & 0.618 & 0.665 & $\mathbf{0 . 8 8 6}$ & 0.723 & 0.556 \\
\hline MF4.1 & 0.635 & 0.693 & 0.733 & $\mathbf{0 . 8 7 0}$ & 0.638 \\
\hline MF4.2 & 0.578 & 0.644 & 0.631 & $\mathbf{0 . 8 5 2}$ & 0.540 \\
\hline MF4.3 & 0.535 & 0.593 & 0.633 & $\mathbf{0 . 8 5 6}$ & 0.602 \\
\hline MF4.4 & 0.563 & 0.610 & 0.589 & $\mathbf{0 . 8 4 1}$ & 0.539 \\
\hline MF4.5 & 0.596 & 0.659 & 0.631 & $\mathbf{0 . 8 3 7}$ & 0.574 \\
\hline MF4.6 & 0.673 & 0.701 & 0.701 & $\mathbf{0 . 8 4 7}$ & 0.567 \\
\hline MF4.7 & 0.636 & 0.647 & 0.739 & $\mathbf{0 . 8 1 7}$ & 0.659 \\
\hline MF4.8 & 0.586 & 0.651 & 0.594 & $\mathbf{0 . 8 0 2}$ & 0.528 \\
\hline MF5.1 & 0.558 & 0.514 & 0.535 & 0.601 & $\mathbf{0 . 9 0 7}$ \\
\hline MF5.2 & 0.606 & 0.559 & 0.522 & 0.632 & $\mathbf{0 . 8 9 5}$ \\
\hline MF5.3 & 0.514 & 0.498 & 0.570 & 0.580 & $\mathbf{0 . 8 1 6}$ \\
\hline & & & & & \\
\hline
\end{tabular}

Results of proposed structural model indicated that the motivation factors to SMS implementation identified all contributed to the project outcomes, as characterized by the operational and safety performance metrics incorporated. The motivation factors including safety commitment by senior management, competency profiles, safety climate, project management, and safety requirements and incentives all positively contributed to the improved safety outcomes of construction projects, in the terms of safe working environment/ conditions, well-operated construction activities, positive indications from key performance indicators, desirable qualities of individuals, well-fitted procedures and manuals, and supportive safety compliance and incentive schemes.

For the motivation factors of SMS implementation, the path coefficient between SMS implementation and project management (MF4) was the greatest, among other motivation factors. It is consistent to the expectation that effective project management could promote and enhance the likelihood of successful SMS implementation. The relevant attributes are well-scheduled and communicated project meetings; effective teamwork and communication between project staff and all stakeholders; well-planned construction works; clear safety organization; strategic control of subcontractors; effective accident investigation arrangement [8,20,23-25]. Consistently, it was also suggested that the communication, team cooperation, project management's commitment and competency were the essential success factor attributes [41]. Besides, this revealed that leadership, teamwork and overall project performance could contribute to the success of SMS implementation [42,43]. 
On the other hand, the path coefficients of competency profile (MF2) and safety climate (MF3) were both the second highest, among other motivation factors. For the competency profiles, the essential attributes were professional qualification and relevant working experiences of the project staff at supervisory and managerial grades, including senior management and safety manager at corporate level, and project manager, safety officer and subcontractors at project level respectively. It was expected that the better understanding on and competency of Occupational Safety and Health (OSH) practice of the safety personnel should facilitate the effective and efficient SMS implementation. In addition, good understanding on OSH practice of relevant stakeholders including government agencies and labours could also stimulate the effective implementation of SMS [8,14,20,33,36,37].

For the effect of safety climate on SMS implementation, this could be attributed to the active participation and engagement of different stakeholders including government agencies, senior management, project management, safety personnel and individual workers [8,20-22,27]. Consistently, safety climate was found correlated to significant risk elimination at workplace and accident prevention respectively $[21,44,45]$. The safety culture could be much improved by embedding the worker engagement during the design and implementation of SMS [46]. This implied the SMS should be developed and implemented as early as the planning stage. This also echoed that the accident rates of the construction industry could be improved if the construction processes were considered at the early planning stage [47]. The current SMS framework mainly focused on the operation stage, thus the framework of SMS should allow flexibility for contractor and client to extend the application of SMS at various stages of a construction project. To encourage such extension of SMS, the developers, contractors and designers should demonstrate their commitment to provide a safer and healthier workplace to all workers and even end-users. Certification bodies of SMS and government should also allow the clients and contractors to adjust their audit schemes in accordance to the project nature and scope of works. Consistently, well implemented management systems could facilitate the development of safer working environment and the generation of better operational outcomes for the organizations $[48,49]$.

\subsection{Proxies for Operational and Safety Performance}

For the project operational and safety outcome, as shown in Table 8, the value of path coefficient between project outcome and desirable qualities of individual (PC4) was the highest. It is consistent to the findings of previous studies that enhanced operational and safety performance were more likely contributed by the qualities of personnel, as reflected by the education level of worker, safety awareness of project manager and senior management, and sense of belonging and safety competence of worker $[23,39]$. Besides, competencies of project manager and safety officer also contributed to the higher qualification of personnel and the positive project outcomes [50,51]. Such results were consistent to that of the studies on the association measure between successful project management, education and training, risk management, and desirbale quality of personnel $[52,53]$.

Table 8. Indicator loading and cross loading of project outcome attributes.

\begin{tabular}{ccccccc}
\hline & PC1 & PC2 & PC3 & PC4 & PC5 & PC6 \\
\hline PC1.1 & $\mathbf{0 . 8 5 7}$ & 0.639 & 0.575 & 0.603 & 0.544 & 0.534 \\
\hline PC1.2 & $\mathbf{0 . 8 5 9}$ & 0.652 & 0.614 & 0.625 & 0.621 & 0.586 \\
\hline PC1.3 & $\mathbf{0 . 8 5 6}$ & 0.687 & 0.650 & 0.612 & 0.575 & 0.536 \\
\hline PC1.4 & $\mathbf{0 . 7 8 4}$ & 0.645 & 0.619 & 0.597 & 0.559 & 0.582 \\
\hline PC2.1 & 0.631 & $\mathbf{0 . 8 3 1}$ & 0.616 & 0.589 & 0.572 & 0.558 \\
\hline PC2.2 & 0.694 & $\mathbf{0 . 8 5 4}$ & 0.691 & 0.670 & 0.632 & 0.569 \\
\hline PC2.3 & 0.657 & $\mathbf{0 . 8 6 4}$ & 0.603 & 0.637 & 0.637 & 0.569 \\
\hline PC2.4 & 0.697 & $\mathbf{0 . 8 9 7}$ & 0.710 & 0.749 & 0.739 & 0.641 \\
\hline
\end{tabular}


Table 8. Cont.

\begin{tabular}{ccccccc}
\hline & PC1 & PC2 & PC3 & PC4 & PC5 & PC6 \\
\hline PC2.5 & 0.640 & $\mathbf{0 . 8 5 3}$ & 0.639 & 0.677 & 0.682 & 0.575 \\
\hline PC2.6 & 0.719 & $\mathbf{0 . 8 7 4}$ & 0.704 & 0.704 & 0.666 & 0.561 \\
\hline PC3.1 & 0.487 & 0.551 & $\mathbf{0 . 7 5 6}$ & 0.541 & 0.562 & 0.518 \\
\hline PC3.2 & 0.585 & 0.608 & $\mathbf{0 . 7 9 4}$ & 0.610 & 0.556 & 0.488 \\
\hline PC3.3 & 0.674 & 0.705 & $\mathbf{0 . 8 9 1}$ & 0.734 & 0.724 & 0.716 \\
\hline PC3.4 & 0.655 & 0.661 & $\mathbf{0 . 8 5 9}$ & 0.754 & 0.717 & 0.675 \\
\hline PC4.1 & 0.595 & 0.563 & 0.648 & $\mathbf{0 . 7 7 8}$ & 0.601 & 0.547 \\
\hline PC4.2 & 0.595 & 0.696 & 0.688 & $\mathbf{0 . 8 6 3}$ & 0.702 & 0.630 \\
\hline PC4.3 & 0.560 & 0.654 & 0.627 & $\mathbf{0 . 8 3 0}$ & 0.686 & 0.670 \\
\hline PC4.4 & 0.670 & 0.723 & 0.738 & $\mathbf{0 . 8 8 0}$ & 0.711 & 0.626 \\
\hline PC4.5 & 0.586 & 0.582 & 0.630 & $\mathbf{0 . 7 8 7}$ & 0.673 & 0.569 \\
\hline PC5.1 & 0.548 & 0.693 & 0.667 & 0.712 & $\mathbf{0 . 8 5 8}$ & 0.671 \\
\hline PC5.2 & 0.671 & 0.716 & 0.717 & 0.739 & $\mathbf{0 . 9 2 1}$ & 0.752 \\
\hline PC5.3 & 0.611 & 0.628 & 0.704 & 0.732 & $\mathbf{0 . 8 9 6}$ & 0.721 \\
\hline PC6.1 & 0.581 & 0.550 & 0.626 & 0.620 & 0.681 & $\mathbf{0 . 8 6 0}$ \\
\hline PC6.2 & 0.592 & 0.591 & 0.628 & 0.620 & 0.690 & $\mathbf{0 . 9 0 8}$ \\
\hline PC6.3 & 0.597 & 0.640 & 0.691 & 0.707 & 0.754 & $\mathbf{0 . 8 8 7}$ \\
\hline & & & & & &
\end{tabular}

Besides, the value of path coefficient between project outcome and well-operated construction activities (PC2) was the second highest among other project outcomes. It could attribute to the benefits correlated to the use of advanced construction method, plant and equipment, logistic on the construction sites (i.e., delivery and storage of construction materials). They all facilitated the project operation, and thus the time efficiency of different construction activities, and more importantly, the effective communication and information dissemination between project manager, supervisor and labours $[20,38,39]$.

In addition, positive key performance indications and well-fitted procedures and manuals also significantly contributed to better project performance. In particular, positive key performance indications could be characterized by decreasing accident rates, sustained low accident rate; good financial performance; high participation rate of safety and health activities and positive safety culture $[20,23]$. Such results were consistent to the previous studies on the association between critical success factors of project management and effective SMS implementation [42,43]. For the well-fitted procedures and manuals, it referred to the clearly-defined safety responsibility, institutional safety accountability, and compliance of operation and safety procedures. They all contributed to the sustained good safety performance of the construction project [20,36,38,39].

The above suggested the positive correlation between successful SMS implementation and good safety performance of construction projects. Indeed, it was also suggested that effective safety risk management could contribute to reduced loss and enhanced profitability of construction project, and thus the sustained improvement of operational and safety performance, whereas the effective risk management could be attributed to understanding on and knowledge of integrated planning approach that entailed the intergation of institutional framework, project scope of work, time schedule, cost schedule, human resource management, risk communication and proceument protocol [27,54]. However, the success of integrated planning approach depended on subjective judgement and professional experience of the management team. It is therefore essential to develop an objective planning and management approach, that incorporate a robust tool for 
safety management-SMS. A robust SMS framework should consist of safety policy, in-house safety rules, safety inspection programme, job hazard control and analysis, incident investigation programme, emergency preparedness programme, and occupation safety promotion and health assurance programmes. As revealed in the current study, a number of motivation factors could significantly contribute to the successful SMS implementation $[8,11,52,54,55]$. Last but not the least, the engagement and coordination among stakeholders, including government agencies, clients and developers, and contractors would be essential to the sustained improvement in operational and safety performance on the construction sites. The engagement could be stimulated by safety awareness campaign and safety training [53].

To sum up, results of the structural model indicated that certain extent of motivation and incentive for the implementation of SMS could possibly alleviate the problems of construction safety, in terms of the operational and safety outcomes. In particular, the influencing motivation factors are the commitment of senior management, competency of project personnel and safety climate and robust project management framework. These factors could have been incorporated into the existing SMS policy framework for the construction industry. On the other hand, safety audit by independent bodies (accredited by the public authority) on a regular time interval could be imposed. For instances, the relevant project outcomes including safe working environment, qualification of individuals, and other possible key performance index should be considered. Besides, the SMS implementation should cover the entire life-cycle process of a construction and management process, from design, planning, construction, operation and management, maintenance, and end-of-life demolishment. Indeed, it was found effective in eliminating the hazards when the safety consideration was incorporated in the design stage. This echoes with the emerging vision of 'design for safety' [56,57]. Last but not the least, for the successful SMS implementation in construction industry, the institutional cooperation among stakeholders including clients (both private developers and public agencies), architects, engineers, contractors, and safety practitioners would be essential.

\section{Conclusions}

Construction is one of the high-risk industries. Since the 1980s, SMS has been introduced to improve the industrial safety round the world by eliminating the possible hazards, reducing injuries and minimizing material loss in different industrial undertakings. However, construction accidents and mortality are rare and random. It is rare that a sizeable sample is available for sensible statistical analysis. This study attempted to evaluate the effectiveness of SMS implementation based on the proxies to operational and safety performance. Also, the moderating factors to the association between quality and level of achievement of SMS and the performance proxies were identified. Results indicated the relationship between SMS implementation and positive project outcomes, based on the empirical data. Since the SMS implementation and operational/safety proxies are latent, a structural model was set out. Results indicated that the five motivation factors of SMS implementation could contribute to the improvement in the operational and safety performance, as revealed by six outcome attributes. This suggested that the existing SMS framework could be enhanced by incorporating a number of relevant incentives. Also, institutional cooperation among clients, engineers, and contractors would be essential, given the constraints of financial budget, and legal and contractual obligation. Findings also implied the optimal resource allocation could be established for sustained improvement in operational and safety performance of the construction sector, given the abovementioned constraints. More importantly, more rigorous institutional reviews could be stimulated on the safety management practice, project operation, and safety education and training protocol by the authority. Stakeholders should demonstrate their safety commitments as early as the planning stage of a construction project. Certification bodies and governments should also allow sufficient flexibility to contactors and clients when conducting a safety audit. Nevertheless, it would be worth exploring the cost effectiveness of SMS implementation in the terms of fiscal gains, when the comprehensive information on the project saving and near-miss incidents is available. 
Author Contributions: The authors confirm contribution to the paper as follows: study conception and design: N.S.N.Y., N.N.S., M.S.; data collection: N.S.N.Y.; analysis and interpretation of results: N.S.N.Y., N.N.S.; draft manuscript preparation: N.S.N.Y., N.N.S., M.S., D.W.M.C., A.P.C.C. All authors reviewed the results and approved the final version of the manuscript.

Funding: This research received no external funding.

Conflicts of Interest: The authors declare no conflict of interest.

\section{References}

1. Leveson, N. A systems approach to risk management through leading safety indicators. Reliab. Eng. Syst. Saf. 2015, 136, 17-34. [CrossRef]

2. Rios Insua, D.; Alfaro, C.; Gomez, J.; Hernandez-Coronado, P.; Bernal, F. A framework for risk management decisions in aviation safety at state level. Reliab. Eng. Syst. Saf. 2016. [CrossRef]

3. Vassie, L.; Tomàs, J.M.; Oliver, A. Health and safety management in UK and Spanish SMEs: A comparative study. J. Saf. Res. 2000, 31, 35-43. [CrossRef]

4. Health and Safety Executive. Successful Health and Safety Management. 2008. Available online: http://crm.foodalert.com/ClientRC/Library/Health\%20and\%20safety/Management\%20of\%20health\% 20and\%20safety/HSG65\%20Successful\%20Health\%20and\%20Safety\%20Management.pdf (accessed on 24 March 2019).

5. Poon, S.; Tang, S.; Wong, F.K. Management and Economics of Construction Safety in Hong Kong: Dynamics of the Residential Real Estate Market in Hong Kong; The Hong Kong University Press: Hong Kong, China, 2008.

6. Yiu, N.S.N.; Chan, D.W.M. A taxonomic review of safety management systems in construction. J. Int. Sci. Publ. Ecol. Saf. 2016, 10, 394-408.

7. Yoon, S.J.; Lin, H.K.; Chen, G.; Yi, S.; Choi, J.; Rui, Z. Effect of occupational health and safety management system on work-related accident rate and differences of occupational health and safety management system awareness between managers in South Korea's construction industry. Saf. Health Work 2013, 4, 201-209. [CrossRef] [PubMed]

8. Robson, L.S.; Clarke, J.A.; Cullen, K.; Bielecky, A.; Severin, C.; Bigelow, P.L.; Mahood, Q. The effectiveness of occupational health and safety management system interventions: A systematic review. Saf. Sci. 2007, 45, 329-353. [CrossRef]

9. Yiu, N.S.N.; Sze, N.N.; Chan, D.W.M. Implementation of safety management systems in Hong Kong construction industry-A safety practitioner's perspective. J. Saf. Res. 2018, 64, 1-9. [CrossRef]

10. Census and Statistics Department. Building, Construction and Real Estate Sectors. 2017. Available online: http://www.censtatd.gov.hk/hkstat/sub/sp330.jsp?tableID=106\&ID=0\&productType=8 (accessed on 12 November 2017).

11. Labour Department. Occupational Safety and Health Statistics; Hong Kong Government: Hong Kong, China, 2018. Available online: http://www.labour.gov.hk/eng/osh/content10.htm (accessed on 24 March 2019).

12. Labour Department. Code of Practice on Safety Management; Hong Kong Government: Hong Kong, China, 2002. Available online: http://www.labour.gov.hk/eng/public/os/manage.pdf (accessed on 24 March 2019).

13. International Labour Organization. Safety and Health at Work. 2018. Available online: http://www.ilo.org/ global/topics/safety-and-health-at-work/lang--en/index.htm (accessed on 12 January 2018).

14. Chan, A.H.; Kwok, W.; Duffy, V.G. Using AHP for determining priority in a safety management system. Ind. Manag. Data Syst. 2004, 104, 430-445. [CrossRef]

15. Park, C.S.; Kim, H.J. A framework for construction safety management and visualization system. Autom. Constr. 2013, 33, 95-103. [CrossRef]

16. Sunindijo, R.Y.; Zou, P.X. Conceptualizing safety management in construction projects. J. Constr. Eng. Manag. 2013, 139, 1144-1153. [CrossRef]

17. Wang, J.; Zou, P.X.; Li, P.P. Critical factors and paths influencing construction workers' safety risk tolerances. Acc. Anal. Prev. 2016, 93, 267-279. [CrossRef] [PubMed]

18. Lam, H.C. An Investigation into the Implementation of Safety Management Systems by Hong Kong Construction Contractors. Ph.D. Thesis, The University of Hong Kong, Hong Kong, China, 2003.

19. International Organization for Standardization. Let the Migration Begin. 2018. Available online: https: //www.iso.org/news/ref2270.html (accessed on 12 January 2018). 
20. Bottani, E.; Monica, L.; Vignali, G. Safety management systems: Performance differences between adopters and non-adopters. Saf. Sci. 2009, 47, 155-162. [CrossRef]

21. Choudhry, R.M.; Fang, D.; Ahmed, S.M. Safety management in construction: Best practices in Hong Kong. J. Profess. Issues Eng. Educ. Pr. 2008, 134, 20-32. [CrossRef]

22. Fan, D.; Lo, C.K.; Ching, V.; Kan, C. Occupational health and safety issues in operations management: A systematic and citation network analysis review. Int. J. Prod. Econ. 2014, 158, 334-344. [CrossRef]

23. Goh, Y.M.; Chua, D. Neural network analysis of construction safety management systems: A case study in Singapore. Constr. Manag. Econ. 2013, 31, 460-470. [CrossRef]

24. Redinger, C.F.; Levine, S.P. New Frontiers in Occupational Health and Safety: A Management Systems Approach and the ISO Model; AIHA Publications: Fairfax, VA, USA, 1996.

25. Redinger, C.F.; Levine, S.P. Development and evaluation of the Michigan Occupational Health and Safety Management System Assessment Instrument: A universal OHSMS performance measurement tool. Am. Ind. Hyg. Assoc. 1998, 59, 572-581. [CrossRef]

26. Edkins, G. The INDICATE safety program: Evaluation of a method to proactively improve airline safety performance. Saf. Sci. 1998, 30, 275-295. [CrossRef]

27. Alsop, P.; LeCouteur, M. Measurable success from implementing an integrated OHS management system at Manningham City Council. J. Occup. Health Saf. Aust. N. Z. 1999, 15, 565-572.

28. Bunn, W.B.; Pikelny, D.B.; Slavin, T.J.; Paralkar, S. Health, safety, and productivity in a manufacturing environment. J. Occup. Env. Med. 2001, 43, 47-55. [CrossRef]

29. Fernández-Muñiz, B.; Montes-Peon, J.M.; Vazquez-Ordas, C.J. Safety management system: Development and validation of a multidimensional scale. J. Loss Prev. Process Ind. 2007, 20, 52-68. [CrossRef]

30. Fernández-Muñiz, B.; Montes-Peón, J.M.; Vázquez-Ordás, C.J. Relation between occupational safety management and firm performance. Saf. Sci. 2009, 47, 980-991. [CrossRef]

31. Krause, T.R. Safety and quality: Two sides of the same coin. Qual. Prog. 1994, 27, 51.

32. LaMontagne, A.; Barbeau, E.; Youngstrom, R.; Lewiton, M.; Stoddard, A.; McLellan, D.; Sorensen, G. Assessing and intervening on OSH programmes: Effectiveness evaluation of the Wellworks-2 intervention in 15 manufacturing worksites. Occup. Environ. Med. 2004, 61, 651-660. [CrossRef]

33. Mohamed, S. Empirical investigation of construction safety management activities and performance in Australia. Saf. Sci. 1999, 33, 129-142. [CrossRef]

34. Yassi, A. Utilizing data systems to develop and monitor occupational health programs in a large Canadian hospital. Methods Inf. Med. 1998, 37, 125-129. [CrossRef]

35. Yu, S.C.; Hunt, B. Safety management systems in Hong Kong: Is there anything wrong with the implementation? Manag. Audit. J. 2002, 17, 588-592. [CrossRef]

36. Ismail, Z.; Doostdar, S.; Harun, Z. Factors influencing the implementation of a safety management system for construction sites. Saf. Sci. 2012, 50, 418-423. [CrossRef]

37. Lu, C.S.; Yang, C.S. Safety leadership and safety behavior in container terminal operations. Saf. Sci. 2010, 48, 123-134. [CrossRef]

38. Moorkamp, M.; Kramer, E.H.; Van Gulijk, C.; Ale, B. Safety management theory and the expeditionary organization: A critical theoretical reflection. Saf. Sci. 2014, 69, 71-81. [CrossRef]

39. Tam, C.; Zeng, S.; Deng, Z. Identifying elements of poor construction safety management in China. Saf. Sci. 2004, 42, 569-586. [CrossRef]

40. Hair, J.F.; Ringle, C.M.; Sarstedt, M. PLS-SEM: Indeed a silver bullet. J. Mark. Theory Pract. 2011, 19, $139-152$. [CrossRef]

41. Shan, M.; Chan, A.P.; Le, Y.; Hu, Y. Investigating the effectiveness of response strategies for vulnerabilities to corruption in the Chinese public construction sector. Sci. Eng. Ethics 2015, 21, 683-705. [CrossRef]

42. Meng, X. The effect of relationship management on project performance in construction. Int. J. Proj. Manag. 2012, 30, 188-198. [CrossRef]

43. Mir, F.A.; Pinnington, A.H. Exploring the value of project management: Linking project management performance and project success. Int. J. Proj. Manag. 2014, 32, 202-217. [CrossRef]

44. Hwang, B.G.; Zhao, X.; Yu, G.S. Risk identification and allocation in underground rail construction joint ventures: Contractors' perspective. J. Civ. Eng. Manag. 2016, 22, 558-767. [CrossRef]

45. Zhao, X.; Hwang, B.G.; Pheng Low, S. Enterprise risk management implementation in construction firms: An organizational change perspective. Manag. Decis. 2014, 52, 814-833. [CrossRef] 
46. Wachter, J.K.; Yorio, P.L. A system of safety management practices and worker engagement for reducing and preventing accidents: An empirical and theoretical investigation. Accid. Anal. Prev. 2014, 68, 117-130. [CrossRef]

47. Goh, Y.M.; Ali, M.J.A. A hybrid simulation approach for integrating safety behavior into construction planning: An earthmoving case study. Accid. Anal. Prev. 2016, 93, 310-318. [CrossRef]

48. Wiengarten, F.; Humphreys, P.; Onofrei, G.; Fynes, B. The adoption of multiple certification standards: Perceived performance implications of quality, environmental and health \& safety certifications. Prod. Plan. Control 2017, 28, 131-141.

49. Pekovic, S. Quality and environmental management practices: Their linkages with safety performance. Prod. Plan. Control 2015, 26, 895-909. [CrossRef]

50. De Silva, N.; Wimalaratne, P. OSH management framework for workers at construction sites in Sri Lanka. Eng. Constr. Archit. Manag. 2012, 19, 369-392. [CrossRef]

51. Hare, B.; Cameron, I. Site manager safety training. Eng. Constr. Archit. Manag. 2011, 18, 568-578. [CrossRef]

52. Akintoye, A.S.; MacLeod, M.J. Risk analysis and management in construction. Int. J. Proj. Manag. 1997, 15, 31-38. [CrossRef]

53. Choudhry, R.M. Behavior-based safety on construction sites: A case study. Accid. Anal. Prev. 2014, 70, 14-23. [CrossRef]

54. Papke-Shields, K.E.; Boyer-Wright, K.M. Strategic planning characteristics applied to project management. Int. J. Proj. Manag. 2017, 35, 169-179. [CrossRef]

55. Zahoor, H.; Chan, A.P.; Gao, R.; Utama, W.P. The factors contributing to construction accidents in Pakistan: Their prioritization using the Delphi technique. Eng. Constr. Archit. Manag. 2017, 24, 463-485. [CrossRef]

56. Behm, M. Linking construction fatalities to the design for construction safety concept. Saf. Sci. 2005, 43, 589-611. [CrossRef]

57. WSH Council. 2018. Design for Safety. Available online: https://www.wshc.sg/wps/portal/!ut/p/a1/04_Sj9CP ykssy0xPLMnMz0vMAfGjzOJ9_E1MjByDDbzdPUIMDRyNfA08QsyNDYPNTIAKInErcA4zJk6_AQ7gaEBIf 7h-FD41YBeAFeCxwks_Kj0nPwns3UjHvCRji3T9qKLUtNSi1CK90iKgcEZJSUGxlaqBqkF5ebleUmZeul5yfq6q ATYNGfnFJfoRyOr0C3JDIwyyTHPKfBwVAS2eqPo!/d15/d5/L2dBISEvZ0FBIS9nQSEh/?action=cmsPublic View\&cmsId=C-2014091001227 (accessed on 24 March 2019). 